\title{
Experiencias
}

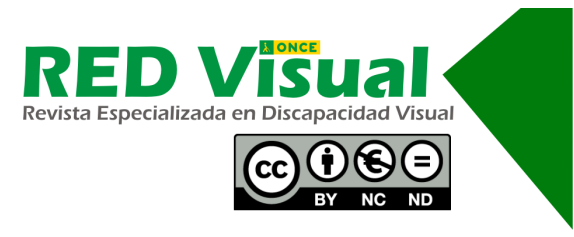

\section{Un club de lectura multisensorial: un proyecto para fomentar la lectura en personas con discapacidad visual ${ }^{1}$}

\author{
Multi-sensorial readers' club: project to encourage \\ people with visual disability to read
}

M. Á. Gil Calmuntia, M. Vallès Altés

\section{Resumen}

Esta experiencia se enmarca en las instalaciones de la Biblioteca de la ONCE de la Delegación Territorial de Cataluña y se ha desarrollado a lo largo de un año con el propósito de hacer más atractiva la lectura a personas con discapacidad visual e incluir elementos, fácilmente identificables con otros sentidos, que tenían que ver con el contexto de las obras propuestas. El objetivo era crear un club de lectura diferente a los habituales y conseguir una mayor inmersión en la lectura utilizando material sonoro, táctil y olfativo adecuado a cada caso. Además, se potenció la interacción entre los participantes, que, en varias ocasiones, colaboraron en la propia organización de la sesión. Los resultados fueron muy satisfactorios y con un alto índice de aceptación y participación por parte de los usuarios, quienes podían elegir cualquiera de los soportes disponibles para realizar la lectura. Sesión a sesión se fue incrementando el interés por esta actividad entre los usuarios, resultando, a día de hoy, la actividad estrella de la biblioteca.

\section{Palabras clave}

Lectura. Bibliotecas. Interdisciplinariedad. Multisensorial. Socialización.

\footnotetext{
1 Trabajo galardonado con el Tercer Premio en el IV Concurso de Experiencias de Innovación y Buenas Prácticas en Servicios Sociales de la ONCE, presentado con el título Club de lectura multisensorial. 


\begin{abstract}
This one-year experience, conducted at ONCE's library at their regional offices in Catalonia, aimed to make reading more appealing to people with visual disability and include elements, readily identifiable with other senses, related to the context of the works recommended. The objective was to create a non-conventional reading club that would contribute to fuller immersion in reading with the audio, tactile and olfactory material best suited to each case. $A$ second aim was to heighten interaction among participants, some of whom became involved in organising several of the sessions. The results were most satisfactory, with a high rate of user acceptance and participation. Club 'members' were invited to use any of the media available to read the works. Interest in this activity, now one of the library's star achievements, grew session by session.
\end{abstract}

\title{
Key words
}

Reading. Libraries. Interdisciplinarity. Multi-sensorial. Socialisation.

\section{Presentación y justificación}

La presente experiencia surgió como consecuencia natural del proyecto que se llevó a cabo en el 2015 en la biblioteca de la Delegación Territorial de la ONCE en Cataluña a fin de convertirla en un referente cultural entre las personas con discapacidad visual usuarias de la misma. A través de varias acciones de incentivación a la lectura y del uso de las salas y los materiales de que se dispone, se consiguió crear un espacio de intercambio que permitió detectar entre nuestros lectores diversas inquietudes en el ámbito literario y en el de la cultura en general. La idea de crear un club de lectura multisensorial nació de algunos comentarios que nuestros usuarios hacían al devolver los libros expresándonos sus opiniones sobre lo leído.

Teniendo en cuenta que en la mayoría de bibliotecas públicas existe un club de lectura, decidimos, como un paso más para ofrecer las mismas oportunidades que cualquier lector tiene en la biblioteca de su barrio, proponer esta actividad a nuestros usuarios y ofrecerles la oportunidad de leer y compartir con otros lectores sus experiencias. Sin embargo, en tanto que todos tenían la posibilidad de integrarse en cualquier club de lectura externo, como de hecho ocurría con unas pocas personas, se quiso dar un giro más original e introducir algunos elementos multisensoriales,

Gil, M.Á., y Vallès, M. (2020). Un club de lectura multisensorial: un proyecto para fomentar la lectura en personas con discapacidad visual. RED Visual: Revista Especializada en Discapacidad Visual, 76, 34-61. https://doi.org/10.53094/UCPO6900. 
a fin de enriquecer mucho más la experiencia lectora, experiencia que fue un éxito desde la primera sesión y que se ha convertido en nuestra actividad estrella. Así, cada mes se propone la lectura de una obra, se concreta una fecha, y se anima a todos los usuarios a participar en el debate y a difundir entre su círculo social el evento a fin de llegar a más público. La obra propuesta tiene que cumplir como requisito indispensable estar disponible en los fondos bibliográficos de la ONCE en los dos soportes: braille y sonoro.

\section{Objetivos}

El principal objetivo de esta experiencia es incentivar la lectura en cualquiera de sus formas (braille y/o sonoro) entre las personas con discapacidad visual, a la vez que, a través de diferentes elementos (táctiles, sonoros y olfativos) que se presentan en la sesión, se produzca una inmersión más profunda en la obra propuesta. Este escenario nos permite crear un espacio de socialización y de intercambio de opiniones, así como incitar a la lectura a aquellos usuarios que aún son un poco reacios a enfrentarse a obras de diferentes géneros. Otro de los objetivos es despertar la curiosidad por los diferentes aspectos que rodean al autor y su obra y que incluyen interacciones con otros campos de la cultura, como la sociología, la política o el arte. Resumiendo, nuestros objetivos son los siguientes:

- Despertar el interés y el placer por la lectura.

- Dar a conocer el material con que cuenta la biblioteca.

- Crear un clima favorable, ameno y positivo hacia la lectura.

- Fomentar el respeto hacia el individuo a través del diálogo y la puesta en común.

- Ampliar el conocimiento, situando al autor y su obra en un breve contexto histórico-social.

- Potenciar la participación de los lectores en el desarrollo del Club de Lectura Multisensorial animándolos a que ellos mismos propongan obras a comentar y/o busquen información del contexto que rodea al autor y su obra. 


\section{Población destinataria}

El Club de Lectura Multisensorial está abierto a todos los afiliados a la ONCE adultos, sean o no usuarios de la biblioteca, y a sus acompañantes. Aunque tienen prioridad todas las personas afiliadas, es interesante que la experiencia cuente con público no afiliado, ya que, de este modo, se realiza a la vez una labor de concienciación a otros sectores de la sociedad.

\section{Temporalización y fechas de realización}

La experiencia se planteó inicialmente por un año, iniciándose en abril de 2018 para hacerla coincidir con la celebración del Día Internacional del Libro. Se escogió el jueves como día de la semana para celebrar los encuentros mensuales, ya que ese día no se solapaba con otras actividades que se suelen realizar en el centro y abría la posibilidad a una mayor afluencia de asistentes. Los meses de agosto y diciembre de 2018 no hubo sesión por la baja afluencia debido al periodo vacacional. En 2019 suprimimos la sesión de marzo, ya que tuvimos que programar la de abril a principios de mes para que no coincidiera con la maratón de lectura que teníamos prevista el día 23 con motivo de la celebración del Día Internacional del Libro de ese año. Así, la relación de obras incluidas en la experiencia ha sido:

- 24 de abril de 2018: Frankenstein, de Mary Shelley.

- 31 de mayo de 2018: Estudio en escarlata, de Arthur Conan Doyle.

- 21 de junio de 2018: El cuento de la criada, de Margaret Atwood.

- 12 de julio de 2018: 20.000 leguas de viaje submarino, de Jules Verne.

- 13 de septiembre de 2018: La ciudad de los prodigios, de Eduardo Mendoza.

- 18 de octubre de 2018: El cartero del rey, de Rabindranath Tagore.

- 22 de noviembre de 2018: Mirall trencat, de Mercè Rodoreda.

- 10 de enero de 2019: El resplandor, de Stephen King.

Gil, M.Á., y Vallès, M. (2020). Un club de lectura multisensorial: un proyecto para fomentar la lectura en personas con discapacidad visual. RED Visual: Revista Especializada en Discapacidad Visual, 76, 34-61. https://doi.org/10.53094/UCPO6900. 
- 28 de febrero de 2019: La elegancia del erizo, de Muriel Barbery.

- 4 de abril de 2019: Sinuhé, el egipcio, de Mika Waltari.

\section{Metodología}

Un buen lector es aquel que comprende el mensaje escrito, deduce cuál ha sido la intención del autor al escribir, tiene fluidez en la lectura, reconoce si está bien o mal redactado, disfruta con lo que lee y elabora opiniones. El colectivo de personas con alguna discapacidad visual no es ajeno a estas expectativas: en lo único en que se diferencia es en el modo de acceder al texto escrito.

Por todo ello, el lema que rige el Club de Lectura Multisensorial es la frase del escritor y crítico literario Edmund Wilson: «No hay dos personas que lean el mismo libro», frase que nos abre la puerta al diálogo y a la interacción.

Las personas que desean participar en la actividad pueden utilizar cualquiera de estos tres soportes para leer la obra:

- Libros sonoros. Existen todo tipo de materias a las que se puede acceder gracias a la grabación en sistema Daisy. Prácticamente un $70 \%$ de los usuarios de la biblioteca utilizan el soporte sonoro por la rapidez y comodidad que les ofrece. A las lecturas propuestas pueden acceder bien a través de la descarga desde la biblioteca digital, bien en sus casas a través del ordenador, o bien a través de la aplicación GOLD, ${ }^{2}$ que cada vez tiene más adeptos. Los usuarios que todavía no manejan las nuevas tecnologías por razones diversas pueden acceder a la obra sonora a través del préstamo presencial en la propia biblioteca o a través de la compra en el Servicio Bibliográfico de la ONCE (SBO). Algunos de los usuarios de este sistema comentan, sin embargo, que pierden el placer de manipular el libro, de interpretarlo a su modo y, en el caso de las personas que utilizan únicamente este sistema, de olvidar cómo se escriben las palabras. Es por este motivo que les proponemos y motivamos a que aprendan el sistema braille.

2 Gestor ONCE de Libros Digitales, aplicación desarrollada por la ONCE y disponible tanto para Android como ios para la lectura de libros Daisy en el teléfono móvil.

Gil, M.Á., y Vallès, M. (2020). Un club de lectura multisensorial: un proyecto para fomentar la lectura en personas con discapacidad visual. RED Visual: Revista Especializada en Discapacidad Visual, 76, 34-61. https://doi.org/10.53094/UCPO6900. 
- Libros en braille. La producción en este sistema es mucho menor en comparación con la producción sonora, debido, por un lado, a los costes y, por otro, a que las peticiones de obra nueva que realizan los usuarios en el SBO (sobre todo los últimos best-sellers) son principalmente en audio. Sin embargo, los lectores habituales en braille comentan a su favor que mejoran su comprensión lectora, que les permiten disfrutar de la lectura de un modo diferente al pasar las hojas o releer una línea, y a afianzar la ortografía y/o aprender cómo se escriben determinados nombres propios, sobre todo extranjeros, ya que, al funcionar muchas veces solo con la referencia auditiva, acaban escribiéndolos, en muchísimos casos, tal como se pronuncian. En su contra solo encuentran el espacio que ocupan los volúmenes, hecho que soluciona la biblioteca al realizar el préstamo y evitar así el almacenamiento en sus hogares.

- Texto en tinta. Esta forma de acceder al libro se circunscribe exclusivamente a todos aquellos afiliados cuyo resto visual se lo permite. Aunque de forma minoritaria, algunos usuarios con bastante resto visual prefieren acceder a la lectura a través del propio libro en tinta o a través de textos digitales que les permiten ampliar la letra a sus propias necesidades. Otros prefieren la ampliación a través de una telelupa, aunque reconocen que, si la lectura es larga o complicada, les comporta un sobresfuerzo que a veces no compensa. Este es el único soporte que la biblioteca no facilita, aunque sí tiene en las salas a disposición de las personas que lo requieran dos telelupas con las que realizar la lectura.

Por lo tanto, el planteamiento básico de la experiencia no implicaba mayor dificultad que la de escoger las obras, por lo que se estudiaron y redactaron unos criterios básicos para hacer la selección de títulos:

1. Que la obra propuesta estuviera disponible en los soportes braille y sonoro para que todos pudieran acceder a ella de la manera que les resultara más cómoda. Esto es cierto que limita un poco el repertorio de títulos, ya que muchas de las novedades se producen en audio, y en braille no siempre encontramos la misma variedad.

2. Que la obra elegida pueda dar pie a plantear diversos temas para el debate, conmemorar acontecimientos de relevancia literaria y/o crear una interrelación con otros eventos culturales que tengan lugar en la ciudad.

Gil, M.Á., y Vallès, M. (2020). Un club de lectura multisensorial: un proyecto para fomentar la lectura en personas con discapacidad visual. RED Visual: Revista Especializada en Discapacidad Visual, 76, 34-61. https://doi.org/10.53094/UCPO6900. 
3. Los títulos son escogidos, en principio, por el personal de la biblioteca, pero los lectores pueden proponer siempre las obras que consideren interesantes, quedando supeditada su inclusión en el programa a su existencia en los fondos bibliográficos de la ONCE.

4. Las obras pueden pertenecer a cualquier género literario, aunque, en la mayoría de ocasiones, los títulos elegidos pertenecieron al de novela, por ser el que mayor aceptación tiene entre todos los lectores.

\subsection{Utilización y elaboración de materiales de apoyo}

Tras elegir los títulos, la siguiente fase del proceso es el estudio de la obra para elegir o elaborar los materiales que permitan convertir el típico encuentro de un club de lectura en una experiencia multisensorial. Para ello, es imprescindible leer la obra y extraer aquellos aspectos representativos de la misma para adaptarlos o buscar materiales que faciliten, a través del tacto, el oído y el olfato, una inmersión más profunda en la narración. Para ilustrar algunas de las obras escogidas nos han sido de gran utilidad las reproducciones en 3D facilitadas por el SBO a las tiflotecas, así como los mapas en relieve que tenemos en las salas. Para algunos títulos, las personas encargadas de la biblioteca elaboramos materiales o adquirimos algunas piezas sencillas (sirva como ejemplo la compra de la gorra y la pipa de Sherlock Holmes; ver Figura 3 en el Apéndice). A nivel sonoro, todos los títulos han contado también con un acompañamiento musical adecuado a la temática y/o el contenido de la obra, así como pequeños efectos especiales cuando la ocasión lo ha requerido. Respecto a la música, se han utilizado cortes de un minuto de una o varias piezas, según los casos, dispuestas en bucle para realizar la bienvenida a la sesión, como se detallará más adelante. También se han utilizado fragmentos de entrevistas emitidas en programas de radio o televisión y que son de carácter público, para escuchar las voces de algunos autores. El sentido del olfato lo hemos cubierto con la ambientación de la sala a través de un humidificador al que se incorporaron esencias, en pequeñas cantidades para que no resultara molesto, escogiendo la que podía ser más representativa para cada uno de los títulos propuestos. Muchos de los olores usados con el humidificador los hemos resuelto con esencias que teníamos en casa o que aportaban los propios asistentes. Por ello, no ha supuesto ningún gasto extra en el presupuesto adjudicado, ya que se trataba de una experiencia y desconocíamos el alcance que tendría. Cabe destacar, sin embargo, que nos ha resultado en ocasiones bastante difícil hallar el material olfativo que deseábamos, recurriendo a veces a materiales habituales, fáciles de encontrar en

Gil, M.Á., y Vallès, M. (2020). Un club de lectura multisensorial: un proyecto para fomentar la lectura en personas con discapacidad visual. RED Visual: Revista Especializada en Discapacidad Visual, 76, 34-61. https://doi.org/10.53094/UCPO6900. 
cualquier hogar, como fue el caso de los algodones impregnados en aceite 3-en-uno. Todos los materiales utilizados serán relacionados más adelante cuando hablemos de las diferentes sesiones.

\subsection{Elección de los títulos y programación}

La primera sesión de esta experiencia tuvo lugar el 24 de abril de 2018. El título seleccionado fue Frankenstein, de Mary Shelley. La elección fue motivada por la conmemoración de los 200 años de la publicación de la novela, pero también se tuvo en cuenta que se trataba de una obra muy conocida a nivel cinematográfico, aunque poco leída en general, lo que facilitaba que los usuarios de la biblioteca se sintieran más motivados a asistir. En este primer encuentro se explicó el alcance de la experiencia y la propuesta de que fuera un Club de Lectura Multisensorial e interactivo, animando a los asistentes a participar, no solo comentando la obra, sino también aportando ideas o sugerencias para futuras sesiones. Se comunicó la voluntad de que estos encuentros tuvieran lugar una vez al mes, estableciéndose que en cada sesión se informaría del siguiente libro a comentar. De este modo, no se presentaba una programación cerrada, sino que se dejaba espacio para que los lectores propusieran títulos, dando un mes de margen para que todos pudiéramos leer el libro.

Para poder arrancar la experiencia haciéndola atractiva para todos, sondeamos la opinión de los usuarios más habituales. La propuesta no solo fue muy bienvenida, sino que nos aportó la colaboración de dos de ellos para la primera obra: uno realizó una breve introducción a la época y el otro una pequeña dramatización, aspectos que se explicarán con más detalle cuando tratemos la sesión en sí.

La siguiente obra programada fue escogida entre varias sugerencias realizadas por lectores interesados en la novela policíaca. Así, surgió el emblemático personaje de Sherlock Holmes, escogiéndose Estudio en escarlata, primera obra de Arthur Conan Doyle en la que aparece este personaje.

En la tercera sesión, escogimos la obra de Margaret Atwood El cuento de la criada por haber cobrado un protagonismo mediático gracias a la emisión de la serie a través de la plataforma HBO.

A lo largo de estos tres primeros meses recibimos muchas sugerencias de obras a comentar por parte de los asistentes, de las que elegimos cinco que cumplían

Gil, M.Á., y Vallès, M. (2020). Un club de lectura multisensorial: un proyecto para fomentar la lectura en personas con discapacidad visual. RED Visual: Revista Especializada en Discapacidad Visual, 76, 34-61. https://doi.org/10.53094/UCPO6900. 
el requisito de estar en los dos soportes: 20.000 leguas de viaje submarino de Jules Verne, La ciudad de los prodigios de Eduardo Mendoza, El cartero del rey de Rabindranath Tagore, Mirall trencat de Mercè Rodoreda y La elegancia del erizo de Muriel Barbery.

La programación de El resplandor, de Stephen King, surgió como consecuencia de una colaboración que realizó la biblioteca con el Centro de Cultura Contemporánea de la ciudad en su exposición sobre Stanley Kubrick. El hecho de que este director siempre basara sus películas en novelas ya existentes nos dio la idea de programar El resplandor, el único título de Stephen King disponible en los dos soportes y que compartía, además, haber sido adaptada al cine por Kubrick.

Respecto a la última obra programada, Sinuhé, el egipcio, de Mika Waltari, fue elegida por haber recibido varias sugerencias por parte de los asistentes de adentrarse en la civilización egipcia, queriendo también rescatar de nuestro fondo un clásico de la novela histórica.

El orden en la programación a partir de la tercera sesión se basó principalmente en criterios temporales, tanto en lo que respecta a ofrecer a los lectores un tiempo mínimo en el que pudieran acabar de leer la obra con comodidad, como al tiempo que necesitaban los participantes que quisieron colaborar en la preparación de las sesiones. Así mismo, se tuvo en cuenta, en el caso de El resplandor, la coincidencia con la exposición sobre Kubrick que hemos mencionado anteriormente.

\subsection{Gestión de los fondos}

Para cada uno de los títulos programados, se comprobaron los fondos disponibles en la biblioteca, solicitando al Servicio Bibliográfico las copias que fueron necesarias en cada caso, tanto en braille como en audio, para cubrir la demanda de préstamo por parte de los usuarios.

\subsection{Difusión de los encuentros}

Tras decidir la obra que se va a comentar cada mes, los usuarios reciben la información por varios canales. La agenda de actividades que se elabora en el centro tiene un espacio dedicado a la biblioteca, en el que se comunica el título de la obra que se comentará, día y hora. En la propia biblioteca se dispone de un 
tablón de anuncios donde se informa del próximo libro, fecha y hora tanto en tinta como en braille. A pesar de que la mayoría de usuarios conocen este panel, no todos acuden a él, por lo que en el mostrador también se expone esta información en tinta y braille, a fin de que, al devolver los libros o recoger nuevos préstamos, la tengan totalmente al alcance. Igualmente, el personal se encarga de recordarles verbalmente el próximo encuentro en esos momentos. También, al finalizar cada una de las sesiones del Club de Lectura, se comunica el próximo título, día y hora del encuentro.

Como no podía ser de otra manera, las sesiones del Club de Lectura Multisensorial se realizan en una de las salas de la biblioteca, haciendo hincapié en todas las comunicaciones de la necesidad de inscribirse para controlar el aforo de la sala.

\subsection{Estructura de las sesiones y materiales utilizados}

Salvo el primero, que se alargó un poco más dado que se presentaba la experiencia, todos los encuentros han tenido una duración máxima de 2 horas y han seguido el siguiente esquema:

- Bienvenida a los asistentes con la música escogida de fondo y ambiente aromatizado con la esencia elegida en el humidificador. Una vez todos situados y antes de empezar la sesión propiamente dicha, se da la referencia musical que se ha utilizado y se quita la música.

- Presentación y contexto histórico de la obra y del autor por parte del personal de biblioteca y/o de los participantes que desearon colaborar. Todo ello no ha de superar los 30 minutos, a fin de tener más tiempo para el debate. Si en esta parte se incluye algún otro elemento, como una audición de la voz del autor o una pequeña dramatización, no debe superar los 5 minutos, que se añadirán a los 30 anteriores.

- Distribución de materiales táctiles con explicación del motivo de su elección, así como de la elección del elemento olfativo.

- Lectura en braille de dos o tres frases extraídas de la obra, o del propio autor, que nos permiten ir introduciendo el debate sobre los temas que se desprenden de la lectura. 
- Coloquio en el que los asistentes expresan su experiencia lectora, lo que les ha sugerido, qué les ha impactado o se dialoga sobre los temas clave que propone la novela. En este momento de la sesión, las personas encargadas de moderar el debate van dando el turno de palabra, según los asistentes la vayan solicitando levantando la mano. Para indicarles que han sido anotados en el turno de palabra, se les toca ligeramente el hombro, para así no interrumpir el discurso de quien está hablando, anotándose también los temas que van surgiendo o que, las mismas moderadoras, proponen para ir conduciendo la tertulia.

- Fin de la sesión y convocatoria del próximo encuentro del Club.

Para todas las tertulias se contó con un ordenador portátil conectado a internet a través del wifi de la biblioteca y dos altavoces conectados al ordenador para reproducir los fragmentos de música escogidos.

La biblioteca también cuenta con un pequeño humidificador que sirvió perfectamente al propósito de crear el ambiente que se buscaba para algunos títulos a través de diferentes esencias. En otras ocasiones se utilizaron diferentes recursos, como incienso, un vapeador o ropa impregnada de aceite lubricante para lograr la sensación olfativa deseada.

\section{Resultados}

Tras todo el trabajo realizado, los resultados han sido altamente satisfactorios en lo referente a la participación. Hemos constatado que las inquietudes de los usuarios de la biblioteca van más allá de la mera lectura de un libro, y que este espacio puede transformarse en un lugar donde, partiendo de la lectura, se estimule a indagar más sobre aspectos interesantes que se desprenden de las sesiones y que nos llevan a leer otros títulos o a buscar más información sobre cuestiones que impactan al lector. A lo largo de estos meses hemos comprobado también que la buena acogida de las primeras sesiones ha hecho que los asistentes hayan difundido estos encuentros entre sus amistades para que los probaran, $y$, en muchos casos, han repetido.

Uno de los aspectos que más hemos de destacar es el interés que se despierta a través de estas sesiones por leer el título propuesto. Si bien muchos de los asistentes se leen la obra, hay un pequeño porcentaje de personas en cada sesión que acude al Club simplemente para escuchar. Esto, que en un principio nos pareció chocante y un

Gil, M.Á., y Vallès, M. (2020). Un club de lectura multisensorial: un proyecto para fomentar la lectura en personas con discapacidad visual. RED Visual: Revista Especializada en Discapacidad Visual, 76, 34-61. https://doi.org/10.53094/UCPO6900. 
poco descorazonador, dada la intención de que fuera algo participativo, redundó en un aumento de la demanda de los títulos propuestos a posteriori, cuando en un principio esas mismas personas habían manifestado que no les apetecía leer la obra propuesta. Tras preguntar el motivo de este cambio, respondieron mayoritariamente que los planteamientos y la visión que se habían dado en la sesión les había despertado el interés de leer la obra, a pesar de saber ya lo que iban a encontrar.

Otro resultado interesante ha sido la «relectura». Tras acabar las sesiones, algunos lectores expresan su intención de volver a leer el título al haber descubierto matices nuevos a raíz de los comentarios y del enfoque de la sesión. Esta situación fue especialmente general en lo que se refiere a la obra de Mary Shelley, Frankenstein, donde todos coincidimos que la impresión que teníamos de esta historia había estado siempre muy condicionada por la versión cinematográfica, siendo que la novela abre la puerta a una visión muy diferente en lo que se refiere a la figura del «monstruo».

A nivel estadístico, hemos obtenido como resultado que las mujeres son las más interesadas en cuanto a asistencia y contenidos, como se ha ido comprobando a lo largo de la experiencia, aunque, curiosamente, han sido exclusivamente hombres quienes se han sentido motivados a colaborar de forma activa en las introducciones sobre el contexto para situar la obra o para buscar elementos de apoyo.

Tabla 1. Participantes del Club de Lectura 2018-2019

\begin{tabular}{|l|c|c|c|}
\hline Sesión & Hombres & Mujeres & Total \\
\hline Frankenstein & 11 & 9 & 20 \\
\hline Estudio en escarlata & 5 & 8 & 13 \\
\hline El cuento de la criada & 5 & 9 & 14 \\
\hline 20.000 leguas de viaje submarino & 7 & 4 & 11 \\
\hline La ciudad de los prodigios & 5 & 6 & 11 \\
\hline El cartero del rey & 3 & 10 & 13 \\
\hline Mirall trencat & 10 & 18 & 28 \\
\hline El resplandor & 5 & 9 & 14 \\
\hline La elegancia del erizo & 5 & 16 & 21 \\
\hline Sinuhé, el egipcio & 4 & 10 & 14 \\
\hline
\end{tabular}

Gil, M.Á., y Vallès, M. (2020). Un club de lectura multisensorial: un proyecto para fomentar la lectura en personas con discapacidad visual. RED Visual: Revista Especializada en Discapacidad Visual, 76, 34-61. https://doi.org/10.53094/UCPO6900. 
En la Tabla 1 y en la Figura 1 vemos claramente que, en la primera sesión, ambos géneros por igual se sintieron atraídos por la experiencia, mientras que en las siguientes sesiones y, sobre todo, con los libros Mirall trencat y La elegancia del erizo, se dispara la afluencia de mujeres. Esto podría ser fácilmente explicable por la temática de las novelas: ambas son historias protagonizadas por mujeres, lo que acerca más el contenido al público femenino. Pero, al margen de este hecho, hemos podido constatar también, a través de los comentarios que se suceden en las propias sesiones o tras ellas, que ha sido mayoritariamente el público femenino el que con más entusiasmo ha animado a otras personas a leer el libro que se proponía y ha divulgado el evento entre su círculo de amistades.

Figura 1. Distribución de participantes por sexos

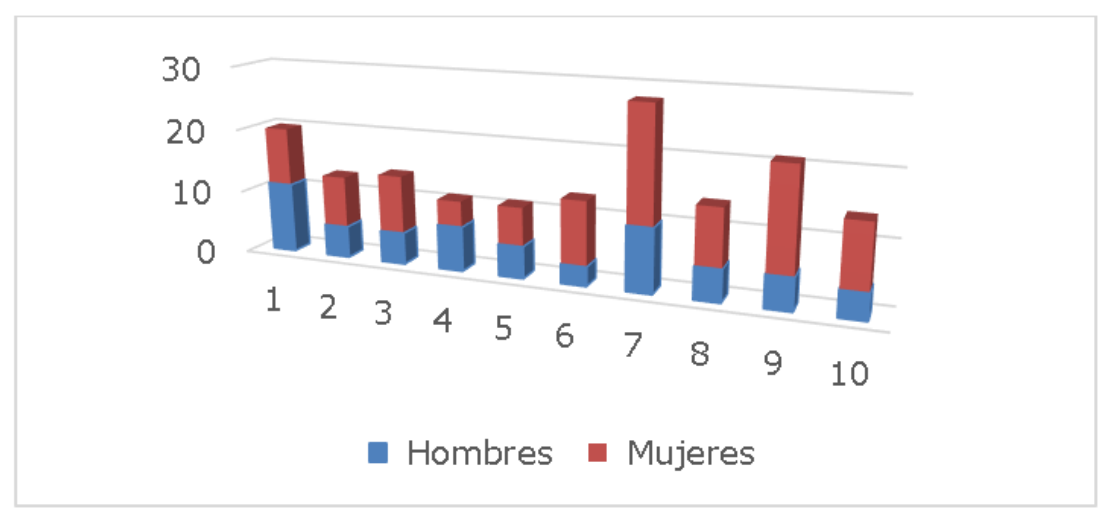

\section{Conclusiones}

Como lectoras de un libro en tinta, hemos podido corroborar que un libro físico, a menudo, nos aporta más información de la que somos conscientes. Cuando una persona coge el volumen en sus manos, lo primero que capta es lo que hay plasmado en la cubierta: título, autor y editorial, pero, principalmente, un diseño con alguna ilustración o fotografía que hace alusión a su contenido. También en su contracubierta, la breve biografía del autor viene acompañada de una foto que nos permite imaginarnos cómo es físicamente esa persona.

Todo esto se pierde irremediablemente cuando se accede a la lectura en audio o en braille. La decisión de incorporar elementos sensoriales que estos soportes no pueden facilitar ha conseguido atraer a más personas a este Club de Lectura Multisensorial. De alguna manera, un olor nos evoca una época, un paisaje, un entorno. Una descrip- 
ción física del autor o del personaje a veces choca porque no casa con su voz. A este respecto, fue curioso el comentario de algunos lectores que decían no imaginarse en absoluto que Conan Doyle tuviera esa voz y ese acento característico al hablar, o que nunca hubieran puesto a la imagen de Mercè Rodoreda una voz con acento francés y más bien grave.

La propuesta de interacción con los asistentes de cara a la lectura y preparación de la tertulia, o en la búsqueda de la información y los recursos asociados a ella, se ofrece también como una alternativa más de tiempo libre, que, aunque se haga de manera individual, toma sentido cuando se comparte con el grupo.

Tras este año de experiencia, acabamos con la satisfacción de haber propiciado que un grupo de 15 personas, como media, se reúnan con ilusión un jueves al mes para comentar y para disfrutar con las sorpresas sensoriales que les preparamos, y que siempre son bienvenidas. La cohesión de sus componentes, además, ha permitido que se conviertan en usuarios activos de las sesiones, y los que han sufrido una pérdida de visión grave en los últimos tiempos se integran con facilidad disfrutando de una afición tan magnífica como la lectura dentro de un marco de normalidad, ya que leer, sentir y compartir es lo que nuestro Club de Lectura Multisensorial ofrece.

M. Ángeles Gil Calmuntia. Técnica de Material Tiflotécnico. Delegación Territorial de la ONCE en Cataluña. Calle Sepúlveda, 1; 08015 Barcelona (España). Correo electrónico: angc@once.es.

Montserrat Vallès Altés. Núcleo Periférico de Servicios Bibliográficos. Delegación Territorial de la ONCE en Cataluña. Calle Sepúlveda, 1; 08015 Barcelona (España). Correo electrónico: mval@once.es.

Gil, M.Á., y Vallès, M. (2020). Un club de lectura multisensorial: un proyecto para fomentar la lectura en personas con discapacidad visual. RED Visual: Revista Especializada en Discapacidad Visual, 76, 34-61. https://doi.org/10.53094/UCPO6900. 


\section{Apéndice \\ Descripción de las sesiones}

\section{Frankenstein de Mary Shelley}

Empezamos dando la bienvenida, mientras suena de fondo la música escogida, para seguir con una breve presentación del Club de Lectura Multisensorial y sus criterios de funcionamiento, informando de su periodicidad, horario y duración prevista. Asimismo, se informa del porqué de esta primera elección: la conmemoración de los 200 años de la publicación de la obra de Mary Shelley. A continuación, se distribuye entre los asistentes el material de apoyo que dará pie a debatir sobre algunos temas que plantea la novela y uno de los colaboradores hace una pequeña dramatización, precedida de un fuerte trueno, recitando el fragmento donde Víctor Frankenstein ve por primera vez al monstruo que ha creado (5 minutos).

Seguidamente, se realiza una introducción del momento histórico en que se escribe la obra (1818) a cargo de uno de los participantes (10 minutos) y una de las moderadoras relata los aspectos más relevantes de la biografía de Mary Shelley (10 minutos).

\section{Temas planteados}

- ¿Quién conoce el mito de Prometeo y por qué se subtitula así el libro?

- Los prejuicios y el rechazo del que es diferente.

- Frankenstein... víctima o verdugo.

- ¿Por qué se conoce al monstruo por el nombre de su creador?

- Diferencias entre la versión cinematográfica y la novela.

Transcurridos más de 90 minutos, damos por cerrada la sesión y convocamos a todos para la lectura del mes siguiente.

\section{Material táctil}

- Láminas fúser, elaboradas por el personal de biblioteca, representando el rostro del monstruo de Frankenstein, tal como quedó inmortalizado por la caracterización cinematográfica (ver Figura 2). 
Figura 2. Material táctil de la sesión de Frankenstein

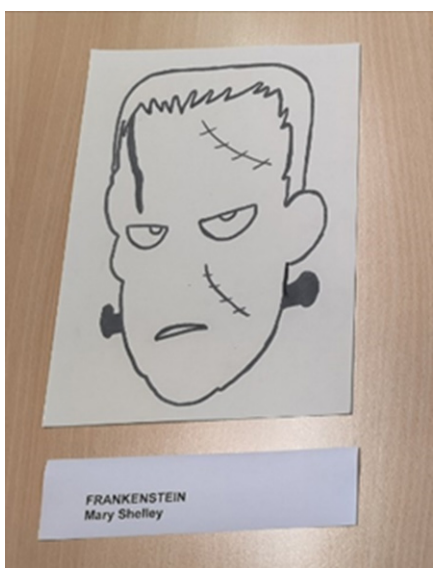

- Dos cartulinas tamaño DIN A4 con frases en tinta ampliada y en braille extraídas del libro, que nos dan pie a introducir el debate:

iQué extraña naturaleza la del conocimiento! Una vez que ha atrapado la mente, se agarra a ella como un liquen sobre la roca. (Monstruo de Frankenstein).

Es difícil creer que el destino de un hombre sea tan bajo que le lleve a nacer solo para morir. (Mary Shelley).

\section{Material sonoro}

- Fantasía de Vaugham Williams, composición perteneciente a la banda sonora de la película Remando al viento (1988), dirigida por Gonzalo Suárez.

- Sonido de trueno, extraído de YouTube, que da paso a la dramatización.

Material olfativo

- Esencia «Bosque y musgo» de Botanicals.

\section{Estudio en escarlata, de Arthur Conan Doyle}

Bienvenida, introducción musical y distribución de los materiales táctiles, explicando de qué se trata y por qué son identificativos del personaje: la gorra característica de Sherlock y la pipa (Figura 3), elementos que se van pasando a los asistentes a fin de que los toquen y se prueben la gorra si así lo desean. También se reparten los textos 
en braille a las personas que han indicado que no les importa leer en voz alta (unos 15 minutos en total).

Figura 3. Material táctil de la sesión de Estudio en escarlata

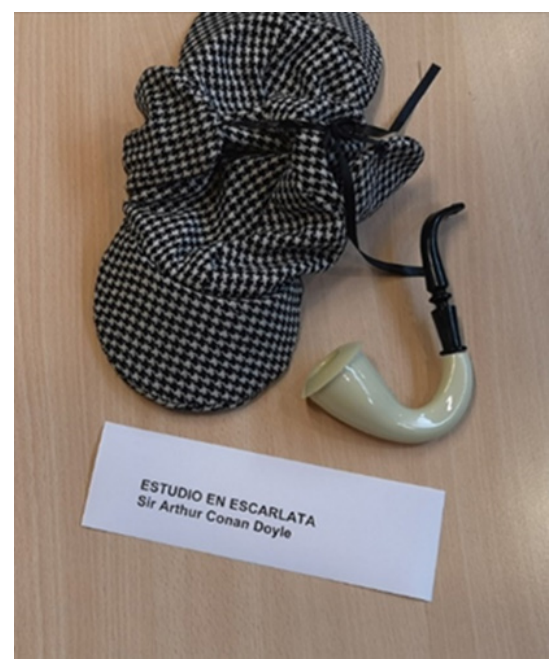

Una de las moderadoras continúa exponiendo la vida de sir Arthur Conan Doyle, describiendo sus características físicas y dando paso a un corte de voz en el que se puede escuchar al autor en inglés (unos 10 minutos en total). Acto seguido, una de las asistentes leyó en braille la traducción (5 minutos).

\section{Temas planteados}

- Personalidades literarias que eclipsan a su autor.

- El método deductivo y el conocimiento especializado.

- Conexiones poco conocidas: Arthur Conan Doyle y Agatha Christie.

\section{Material táctil}

- Deerstalker o cervadora (sombrero de cuadros usado por el detective Sherlock Holmes).

- Pipa.

- Cartulinas impresas en tinta ampliada y braille con dos frases del personaje principal: 
El cerebro es como una pequeña habitación vacía que vamos amueblando con elementos de nuestra elección.

Existe una roja hebra criminal en la madeja incolora de la vida, y nuestra misión consiste en desenredarla, aislarla y poner al descubierto sus más insignificantes sinuosidades.

\section{Material sonoro}

- David Arnold y Michael Price, Sherlock (Original Television Soundtrack) de la serie Sherlock de la BBC, producida en 2010.

- Corte de voz de sir Arthur Conan Doyle extraído de un vídeo de 1927. Del contenido de la entrevista se realizó la traducción y transcripción al braille.

Material olfativo

- Olor a tabaco de pipa conseguido con el líquido para vapear «Burley Tobacco» (tabaco de pipa dulce extra aromático) reforzando la imagen de Sherlock con su eterna pipa en la boca.

\section{El cuento de la criada, de Margaret Atwood}

Figura 4. Material táctil de la sesión de El cuento de la criada

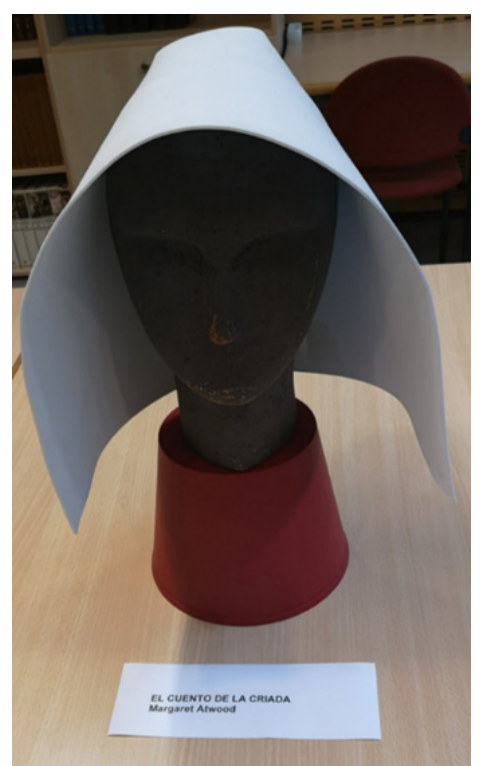

Gil, M.Á., y Vallès, M. (2020). Un club de lectura multisensorial: un proyecto para fomentar la lectura en personas con discapacidad visual. RED Visual: Revista Especializada en Discapacidad Visual, 76, $34-61$. https://doi.org/10.53094/UCPO6900. 
Bienvenida y explicación del porqué de la elección de los elementos (Figura 4): tocado que aísla a las criadas cuando salen de la casa y que se ha confeccionado en la biblioteca con goma EVA (foamy). Se les da a los asistentes para que se lo vayan colocando y comprueben la sensación que produce. Tanto hombres como mujeres coinciden en la sensación de aislamiento y opresión que notan.

Mientras, se explica que se han colocado los cuencos con bolas antipolillas para crear la sensación de limpieza y cuidado de las casas. Breve explicación del contexto histórico-social de la novela y lectura en voz alta de dos frases en braille: una pronunciada por la propia autora en una entrevista y otra pronunciada por June en la novela.

En El cuento de la criada no escribí nada que la gente no haya hecho ya en este planeta. (Margaret Atwood).

Ahora estoy despierta al mundo. Estaba dormida antes y así es como lo dejamos pasar. Cuando atacaron el Congreso, no nos despertamos. Cuando culparon a los terroristas y suspendieron la Constitución, tampoco nos despertamos. Dijeron que sería temporal. Nada cambia de golpe. Si estuvieras en una bañera que se calienta poco a poco, morirías hervida sin darte cuenta. (June-Defred).

\section{Temas planteados}

- Definición de novela distópica.

- Sometimiento de la mujer, esclavitud, censura... Comparación con los tiempos que vivimos.

- La indolencia social y la manipulación.

- Los códigos y simbología del vestuario.

\section{Material táctil}

- Reproducción del tocado de las criadas confeccionado con goma EVA.

\section{Material sonoro}

- Lesley Gore, You don't own me (1964), canción que se convirtió en un himno del movimiento feminista. 
- Radiohead, Creep (versión de Scala \& Kolacny Brothers).

\section{Material olfativo}

- Tres cuencos con «Bolas antipolillas ropa limpia» marca Orión, dispuestos en el centro de la mesa.

\section{20.000 leguas de viaje submarino, de Jules Verne}

Bienvenida mientras se escucha una reproducción del sonido del mar y el pitido de un sónar. Reparto de material táctil para apreciar la forma del Nautilus y contextualización de la obra de Verne (Figura 5).

Figura 5. Material táctil de la sesión de 20.000 leguas de viaje submarino

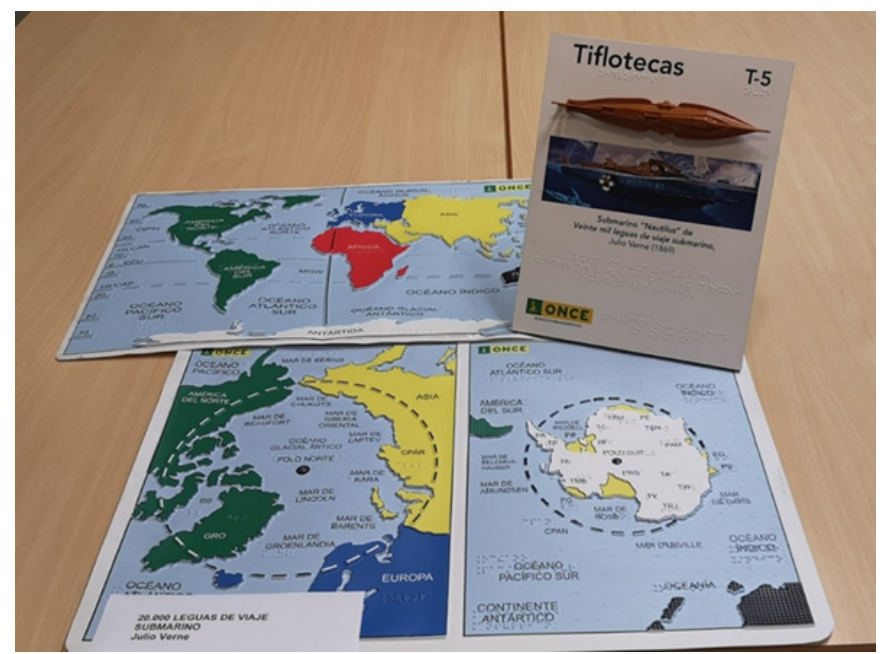

Temas planteados

- Sociedad de la Niebla.

- Origen del nombre Nemo y simbología del personaje.

- Hasta qué punto Verne inventó realmente o se nutrió de otros inventos.

- Verne, un hombre adelantado a su tiempo.

Material táctil

- Nautilus confeccionado en 3D por el SBO (n.0 5 de la colección Tiflotecas).

Gil, M.Á., y Vallès, M. (2020). Un club de lectura multisensorial: un proyecto para fomentar la lectura en personas con discapacidad visual. RED Visual: Revista Especializada en Discapacidad Visual, 76, 34-61. https://doi.org/10.53094/UCPO6900. 
- Adaptación del diseño del interior del submarino reproducida con horno fúser.

- Mapas en relieve (mapamundi y círculos polares) para mostrar el recorrido del Nautilus en la novela.

Material sonoro

- El pitido de un sónar.

- Sonido del oleaje marino.

- Fragmento de la película 20.000 leguas de viaje submarino (1954), producida por Walt Disney y protagonizada por Kirk Douglas y James Mason, en la que el capitán Nemo interpreta al órgano Tocata y fuga en re menor de Johann Sebastian Bach.

\section{Material olfativo}

- Esencia aromática «Algas marinas» de la marca Gran Velada.

\section{La ciudad de los prodigios, de Eduardo Mendoza}

Bienvenida con música de Albéniz y explicación de la elección. Olfativamente, se sugiere la sociedad industrial que se plasma en la novela. En esta ocasión, la sesión fue preparada casi en su totalidad por uno de los afiliados asistentes, quien había propuesto esta lectura y se encargó de hacer toda la introducción sobre el autor y la obra, incluidos varios cortes de voz donde pudimos escuchar al propio autor.

\section{Material táctil}

- Maqueta del Arco del Triunfo de la ciudad donde transcurre la trama del libro.

\section{Material sonoro}

- Isaac Albéniz, Barcarola, op. 23 (1883).

- Cortes de voz del escritor en una entrevista a propósito de La ciudad de los prodigios. 


\section{Material olfativo}

- Un cuenco con algodones impregnados de «Aceite multiusos 3-en-uno».

\section{El cartero del rey, de Rabindranath Tagore}

Bienvenida con varios fragmentos en bucle de música hindú. En el humidificador, esencia de curry, por ser uno de los aromas más conocidos de esta cultura. En esta ocasión también fue un afiliado quien había propuesto esta obra de teatro y se encargó de toda la introducción histórico-social del autor y su obra, siendo una parte muy importante en la conducción del debate. A lo largo de la sesión, escuchamos poesías recitadas por el propio autor.

\section{Temas planteados}

- Aclarar el significado de algunas palabras desconocidas, como ajorcas, champaca, biznagas y otras.

- Ausencia de descripciones.

- Concepto de la muerte: diferencia entre Oriente y Occidente.

- Valor del presente.

- ¿Por qué un niño y por qué la edad de 7 años? Simbología del número 7.

\section{Material táctil}

- Lámina fúser de la palabra «Tagore» escrita en sánscrito.

- Texto en braille de la traducción de la canción escrita, compuesta y cantada por el propio Tagore Tabu Mone Rekho (Acuérdate de mí).

\section{Material sonoro}

- Tagore medley: a tribute to Rabindranath Tagore.

- Varios autores, Bengali songs (2014).

Gil, M.Á., y Vallès, M. (2020). Un club de lectura multisensorial: un proyecto para fomentar la lectura en personas con discapacidad visual. RED Visual: Revista Especializada en Discapacidad Visual, 76, 34-61. https://doi.org/10.53094/UCPO6900. 
- Jana-Gana-Mana (El espíritu de todo el pueblo). Himno nacional de la India.

- Rabindranath Tagore, Tabu Mone Rehko (1932).

- Grabación en formato MP3 de algunas poesías de Rabindranath Tagore, leídas por profesionales, que escogió el afiliado que condujo la tertulia.

\section{Material olfativo}

- «Aceite esencial hoja de curry» de Mystic Moments.

\section{Mirall trencat, de Mercè Rodoreda}

Bienvenida con música de violín y ambientación de la sala con aroma de jazmín. Justificación de las elecciones (violín por la profesión de uno de los personajes y jazmín por el gusto a las flores de la autora).

Esta obra fue propuesta por uno de los asistentes más habituales, quien se encargó de hacer un breve repaso a la biografía de la autora después de interpretar una versión dramatizada, escrita e interpretada por él mismo, del final de la novela (5 minutos).

También nos leyó un relato corto titulado La carta (5 minutos), que sirvió para introducir el contexto histórico y biográfico de la autora, así como una breve grabación donde pudimos escuchar su voz.

\section{Temas planteados}

- Infancia de Rodoreda y su reflejo en la novela.

- Motivos por los que una madre abandona al hijo.

- Facetas desconocidas de la autora como pintora y poeta.

- Burguesía y decrepitud.

\section{Material táctil}

- Fúser de uno de los dibujos de Mercè Rodoreda. Sus dibujos son lineales y con un toque naíf, por lo que entendimos que eran fáciles de percibir acompañados de una pequeña explicación. 


\section{Material sonoro}

- Johannes Brahms, Vals op. 39 (1930). Interpretado al violín por Tossy Spiwakowsky.

- Fragmento de la entrevista que realizó Joaquín Soler Serrano a la autora en el programa $A$ fondo (1980), en el que habla de su abuelo y su amor por los jardines.

- Efecto sonoro de ruido de cristales rotos al final de la dramatización.

\section{Material olfativo}

- Aceite esencial de jazmín «White Jasmin» de Botanicals.

\section{El resplandor, de Stephen King}

Bienvenida con la música de la película de Kubrick y aroma a vino haciendo referencia al alcoholismo del protagonista. La programación de esta obra, motivada por la colaboración de la biblioteca con una exposición sobre Kubrick en la ciudad. Para trabajar las diferencias entre novela y adaptación cinematográfica en la sesión, proyectamos una semana antes la película con audiodescripción que tenemos en la biblioteca.

Una de las moderadoras hizo un repaso por la biografía de Stephen King, donde se puso de manifiesto la influencia que tuvo esta sobre El resplandor. Se hace referencia al porqué de este título, inspirado por una canción de John Lennon, y se lee, en braille, la traducción de la letra de la canción (5 minutos).

También se repasó la relación que hubo entre King y Kubrick a propósito de la adaptación de la novela al cine y de la famosa frase: «Here's Johnny!».

Lectura en braille de una frase extraída de la novela y que da pie al debate:

De un extraño te puedes apartar, pero de ti mismo no.

\section{Temas planteados}

- Diferencias libro-película: Stephen King - Stanley Kubrick.

- Locura, soledad, aislamiento. 
- Teorías conspiratorias acerca del libro y la película.

- Alcoholismo.

\section{Material táctil}

- Máquina de escribir antigua marca Olivetti Lettera 32 prestada por uno de los asistentes para la sesión.

- Cartulina tamaño DIN A4 con la frase propuesta para el debate y un par de páginas en braille con la traducción de la canción Instant karma.

\section{Material sonoro}

- Wendy Carlos \& Rachel Elkind, The shining (tema principal de la película) (1980).

- John Lennon, Instant karma (1970), que inspiró el título del libro.

\section{Material olfativo}

- Tres cuencos con ropa vieja impregnada con vino tinto de mesa.

\section{La elegancia del erizo, de Muriel Barbery}

Bienvenida con varios cortes de música francesa. Se da a los asistentes la referencia de la música utilizada, así como el motivo del aroma a chocolate que se ha utilizado esta vez: la afición al chocolate de Renné, la portera. Breve presentación de la autora, profesora de filosofía en la UIMP de Saint Lô y lectura en braille de dos frases extraídas de la novela y que sirven para ir introduciendo las reflexiones sobre lo leído:

Quizá estar vivo sea esto: perseguir instantes que mueren.

Cuánto mejor sería si compartiéramos unos con otros nuestra inseguridad, si todos juntos nos adentráramos en nosotros mismos para decirnos que las judías verdes y la vitamina $\mathrm{C}$, si bien alimentan al animal que somos, no salvan la vida ni sustentan el alma.

\section{Temas planteados}

- La muerte como puerta de entrada a diferentes situaciones.

- El mundo de las apariencias. 
- La belleza de las pequeñas cosas.

- Arquetipos sociales.

\section{Material táctil}

- Maqueta de gran tamaño de la Torre Eiffel.

- Dos cartulinas tamaño DIN A4 con las frases propuestas en tinta ampliada y braille.

\section{Material sonoro}

- Edith Piaf, Sous le ciel de Paris (1954).

- Mireille Mathieu, Le dernière vals (1967).

- Charles Aznavour, La Bohème (1966).

- Corte de voz de Muriel Barbery de unos 15 segundos extraído de una entrevista en la televisión francesa.

\section{Material olfativo}

- Esencia «Cacao Oil» de Piping Rock.

\section{Sinuhé, el egipcio, de Mika Waltari}

Bienvenida con la música elegida e información sobre lo que estamos escuchando. En esta ocasión tenemos muchos elementos táctiles, por lo que se distribuyen sobre la mesa y se van explicando y pasando en círculo para que todos puedan situarse.

Una de las moderadoras hace una breve introducción histórica sobre el autor y el periodo histórico del antiguo Egipto que abarca la novela, así como algunos comentarios sobre los conocimientos avanzados que esta civilización tenía, tal como se desprende de la lectura.

Una de las asistentes lee en braille una frase pronunciada por Sinuhé en la novela para dar pie al debate:

La verdad es un cuchillo afilado, la verdad es una llaga incurable, la verdad es un ácido corrosivo. 


\section{Temas planteados}

- Relación de amistad entre Sinuhé y Kaptah y su paralelismo con don Quijote y Sancho Panza.

- El concepto de «verdad» y quién la controla.

- Consecuencias del amor y la pasión.

- Los diferentes Sinuhé en el libro: médico, espía, cronista, descreído.

- La medicina y la alimentación en el Antiguo Egipto.

Material táctil

Figura 6. Material táctil de la sesión de Sinuhé, el egipcio

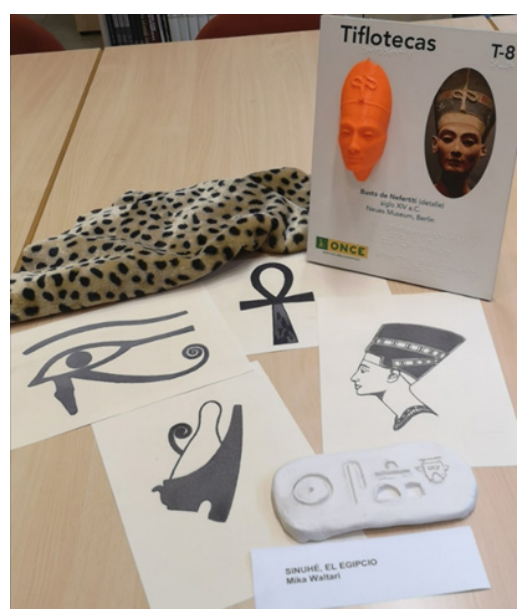

- Representación en 3D de Nefertiti de la colección Tiflotecas (n.0 8).

- Láminas fúser de:

- Tocado de Nefertiti de perfil, que permite comprobar su cráneo alargado.

- Corona del Alto y Bajo Egipto.

- Ojo de Horus y Ankh o cruz egipcia. 
- Figuras aportadas por varios asistentes a la sesión: esfinge, las pirámides, la diosa Bastet -que tiene forma de gato-, el sarcófago de Tutankhamon y un escarabeo o escarabajo sagrado.

- Mapa en relieve de África para ver la situación de Egipto.

- Cartucho hecho en arcilla por el personal de biblioteca con el nombre del faraón Amenenhat I extraído del jeroglífico que cuenta la historia original de Sinuhé.

- Piel de leopardo con la que se vestían los sumos sacerdotes.

Material sonoro

- The Mystic Sound Orchestra, Pharaoh: the sound of mystery, vol. 1 (2009).

Material olfativo

- Una varilla de incienso de sándalo. 